This paper is a postprint of a paper submitted to and accepted for publication in IET Electric Power Applications and is subject to Institution of Engineering and Technology Copyright. The copy of record is available at IET Digital Library

\title{
Evaluation of Saliency Tracking as an Alternative for Health Monitoring in PMSM-Drives under Nonstationary Conditions
}

\author{
J. Arellano-Padilla ${ }^{1}$, M. Sumner ${ }^{2}$, C. Gerada ${ }^{3}$ \\ Department of Electrical and Electronic Engineering \\ University of Nottingham; Nottingham, UK \\ jesus.arellano@nottingham.ac.uk ${ }^{1} ; \underline{\text { mark.sumner@nottingham.ac.uk }}{ }^{2} ;$ chris.gerada@ nottingham.ac.uk $^{2}$
}

\begin{abstract}
This paper evaluates the capability of saliency tracking to assess the health condition of permanent magnet synchronous motor (PMSM) drives operating under nonstationary conditions. The evaluated scheme is based on saliency tracking methods, which are associated to the accurate sensorless control of AC drives without zero speed limitations. In this work two representative saliency tracking architectures are evaluated:
\end{abstract} High Frequency (HF) injection, and PWM transient excitation. Although a monitoring approach based on HF injection was previously reported, a comparative study to evaluate the most representative saliency tracking schemes to assess health condition in drives was still missing. The aim of this work is to fill out this gap by evaluating and comparing two saliency-based monitoring schemes (one based on HF-injection and the other based on PWM transient excitation) to evaluate their performance in the presence of inter-turn winding faults.

Simulation and experimental results are presented which confirm that both schemes offer excellent detection capabilities and that are suitable for drives operating under nonstationary conditions including standstill operation. Significant differences are also found for instance, PWM transient excitation offers improved accuracy since the approach is not affected by the inverter nonlinearities and is suitable for full-speed range applications. The main drawback here is complexity and the hardware requirements. Schemes based on HFinjection proved to be very simple and provide comparable results; however a good performance is only guaranteed for the zero-to-medium speed range applications which limit their applicability.

\section{INTRODUCTION}

One of the most critical components in electrical drives is the stator winding insulation. Recent surveys have shown that the percentage of failures due to problems with the stator insulation is in the range of 26-36\% [1-3]. Insulation breakdown is usually related to thermal, electrical, mechanical, or environmental stress [4]. In most cases insulation deterioration begins with the appearance of a turn-to-turn fault where two or more adjacent coils become short circuited. At this stage little can be observed externally, however currents in the affected turns may become substantially higher than the operational currents which may produce hot spots. These faults may quickly degrade into severe failures if left unattended [5-6]. Several alternatives aimed at the detection of winding faults have been proposed [5]; some of them are very reliable but normally fail to identify certain faults particularly in drives operating under nonstationary or standstill operation. This is because in most cases conventional schemes rely on Discrete Fourier Transform (DFT), which is undesirable.

Since saliency tracking methods has proved to be very sensitive to track the magnetic characteristics of drives operating under nonstationary conditions (accurate sensorless control of low saliency machines has been achieved [9]), it is expected that a similar performance could be obtained to assess the drive condition, this since electromagnetic faults may produce changes in saliency. This assumption was confirmed in [7], where a 
monitoring scheme based on HF-injection was developed. Despite the excellent capabilities reported, the approach was restricted to the zero-medium speed region. This is due to practical limitations inherent to HFinjection (the maximum carrier frequency that can be applied while keeping accurate performance).

For the full speed range applications, accurate sensorless performance has been achieved by PWM-transient excitation [11-13]. Considering that in this case detection of saliency is not limited by the speed range, it is correct to assume that a monitoring scheme based on PWM-transient excitation is a suitable option to assess the health condition independently of the speed range. This assumption is investigated in detail by implementing a monitoring scheme based on the INFORM methodology. Further, the approach is compared against the scheme reported in [7] as a method to identify main advantages and characteristics of each topology.

Organisation of the paper is as follows: Section II provides a brief overview of conventional methods aimed to the on-line detection of winding faults; Section III briefly describes theoretical concepts related to HF-injection and PWM transient excitation. The saliency-based monitoring approach used is briefly described. Section IV contains numerical and experimental results of the evaluated schemes, in this case the presence of inter-turn winding faults is considered. Conclusions are contained in Section VI.

\section{SCHEMES FOR WINDING CONDITION MONITORING}

Several schemes aimed to the detection of winding faults are found in literature; offline methods are more direct and accurate [11] however can only be applied to motors disconnected from service. On-line monitoring is preferred since the health condition is assessed while the machine is in operation. Traditional schemes include: temperature tracking, measurement of sequences, and signature analysis. Temperature monitoring [12] requires thermocouples embedded within the stator windings however detection of winding faults at early stage of development is unlikely, unless the embedded sensor is located very close to the affected area (hot spot). Several schemes related to the estimation of the machine temperature have been reported, in most cases these methods are based on electrical models and observers [30], Detection of incipient faults is unlikely due to limited sensitivity. Schemes based on sequence measurement have been proposed for the detection of winding where measurements of impedance [15], currents [16], or voltages [17] are the most common. These methods have proven to be very successful for motor fed by the grid however are not suitable for servodrives.

For the case of machines fed by power converters, schemes based on signature analysis are preferred. These methods assume that new harmonic frequencies are created in the presence of faults which involve detection of certain harmonic components. The more representative signature analysis methods are based on current [18], vibration [19], and axial leakage flux measurements [20]. Signature analysis based methods require the extraction of the harmonic content through DFT methods which require steady state operation.

Some advanced solutions are able to assess the condition of the drive under nonstationary conditions; these methods are based on pattern recognition techniques and wavelets. For instance, in [21] an approach based on complex gauss wavelets is applied to the instantaneous power measurement of a nonstationary drive. Excellent results are obtained however the approach is not suitable for standstill operation. In [22] an approach based on an extended Kalman filter shows a quick response and an excellent detection capability however fails also under standstill operation.

Some advanced schemes use HF injection to monitor the condition of the drive; for instance in [23] aging and deterioration of the winding insulation is monitored by the detection of changes in the turn-to-turn capacitance. The scheme has the potential to be used for full operating conditions; however considering that the frequency of 
the carrier signal should be in the range of the resonance characteristics (MHz), the scheme becomes impractical considering external power supplies are required to inject the carrier component. An interesting approach based on HF-injection [24-25], uses the resulting HF negative sequence to assess the condition. This is relevant since sequence measurement methods were restricted until now, for line-fed machines. The scheme has the potential to be used for standstill operation; however require DFT to improve accuracy in the presence of incipient faults. Next section presents applicability of saliency tracking as alternatives to assess the drive condition.

\section{SALIENCY-BASED CONDITION MONITORING}

The tracking of anisotropic properties of the rotor geometry by leakage inductance modulations has become a standard mechanism for rotor position estimation [9-10]. According to [25], the modulated leakage inductances of a PM machine can be modelled by (1) if the rotating reference frame $(d q)$ is considered:

$$
L_{\sigma d q}^{r}=\left[\begin{array}{cc}
L_{\sigma d} & 0 \\
0 & L_{\sigma q}
\end{array}\right]=\left[\begin{array}{cc}
L_{\sigma}+\Delta L & 0 \\
0 & L_{\delta}-\Delta L
\end{array}\right]
$$

where $L_{\sigma d}$ and $L_{\sigma q}$ are the transient leakage inductances, with $L_{\sigma}=\left(L_{\sigma d}+L_{\sigma q}\right) / 2$ and $\Delta L=\left(L_{\sigma d}-L_{\sigma q}\right) / 2$ representing the variations of inductance due to the saliency modulation. Since this modulation should be extracted from the machine currents, (1) can be transformed into a stationary frame which gives:

$$
L_{\sigma \alpha \beta}^{s}=\left[\begin{array}{c}
L_{\sigma \alpha} \\
L_{\sigma \beta}
\end{array}\right]=\left[\begin{array}{cc}
L_{\sigma}+\Delta L \cos \left(\theta_{\delta}\right) & \Delta L \sin \left(\theta_{\delta}\right) \\
\Delta L \sin \left(\theta_{\delta}\right) & L_{\delta}-\Delta L \cos \left(\theta_{\delta}\right)
\end{array}\right]
$$

where $\theta_{\delta}$ is the saliency angle determined by saturation and the rotor anisotropic geometry. The aim is to extract information of the saliency characteristics (determined by $\theta_{\delta}$ ) as a method not only to estimate the rotor position, but to assess the condition of the drive. Saliency is affected in the presence of winding faults since configuration of the stator changes. For instance, the presence of inter-turn faults produces unbalances in the resistance and produce changes on inductances $\Delta L$ and $\mathrm{L}_{\delta}$ (see (2)). This occurs because the number of effective turns is reduced. Additionally, the total flux is reduced due to the opposite flux generated by the induced currents in the short-circuited turns. The total effect is observed externally as a reduction of inductance.

Two schemes to extract the saliency characteristics are available: HF-injection [8-10], and PWM transient excitation [11-14]. Note that a monitoring scheme based on HF-injection was developed by these authors and reported in [7], therefore this work focuses on the INFORM methodology which is a conventional scheme related to PWM transient excitation. Both schemes are briefly reviewed in this paper, however due to space constraints details are maintained to a minimum (suggested literature is proposed).

\subsection{Short Description of HF-Injection}

This approach injects a carrier signal $\left(\omega_{\mathrm{c}}\right)$ superimposed on the fundamental voltage and uses the resulting current modulation to estimate the saliency angle $\left(\theta_{\delta}\right)$. The carrier signal (a balanced three-phase rotating vector) can be represented as in (3), where $V_{c}$ is the applied signal, while $\omega_{c} t=\theta_{c}$ is the carrier frequency.

$$
\left[\begin{array}{l}
v_{\alpha c} \\
v_{\beta c}
\end{array}\right]=V_{c}\left[\begin{array}{c}
-\sin \left(\omega_{c} t\right) \\
\cos \left(\omega_{c} t\right)
\end{array}\right]
$$

According to [26], the carrier currents can be represented as: 


$$
i_{c}=\left[\begin{array}{c}
i_{c \alpha} \\
i_{c \beta}
\end{array}\right]=\frac{V_{c}}{\omega_{c} L_{\sigma d} L_{\sigma q}}\left[\begin{array}{c}
L_{\sigma} \cos \left(\omega_{c} t\right)+\Delta L \cos \left(\theta_{\delta}-\omega_{c} t\right) \\
L_{\sigma} \sin \left(\omega_{c} t\right)+\Delta L \sin \left(\theta_{\delta}-\omega_{c} t\right)
\end{array}\right]
$$

where that the modulated current depends of the carrier voltage, the injection frequency $\left(\omega_{\mathrm{c}}\right)$, and inductances $\left(\mathrm{L}_{\sigma \mathrm{d}}, \mathrm{L}_{\sigma \mathrm{q}}, \mathrm{L}_{\sigma}\right)$. The saliency modulation is related to $\Delta L=\left(L_{\sigma d}-L_{\sigma q}\right) / 2$ which is determined by $\theta_{\delta}$ as observed in (4). Assuming that (3) can be represented as $V_{c}=u_{c} e^{j \omega_{c} t}$, (4) can be conveniently rewritten as:

$$
i_{c}=\frac{u_{c}}{\omega_{c} L_{\sigma d} L_{\sigma q}}\left(L_{\sigma} e^{j \omega_{c} t}+\Delta L e^{j\left(-\omega_{c} t+\theta_{\delta}\right)}\right)=\mathrm{i}_{c p}+\mathrm{i}_{c n}+\mathrm{i}_{c z}
$$

As observed from (5), it is evident that the resulting carrier signal consists of three main components: the positive sequence $i_{c p}$ that rotates in the same direction as the carrier signal, the negative sequence $i_{c n}$ that rotates in the opposite direction; and the zero sequence $i_{c z}$ (this component exists only in unbalanced systems [25]). From (5), it is clear that $i_{c n}$ is the relevant component relevant since contains information related to $\theta_{\delta}$. In [11] a homodyne demodulator is used to remove the influence of $\mathrm{i}_{c p}$ and $\mathrm{i}_{c z}$, this approach is shown in Fig.1.

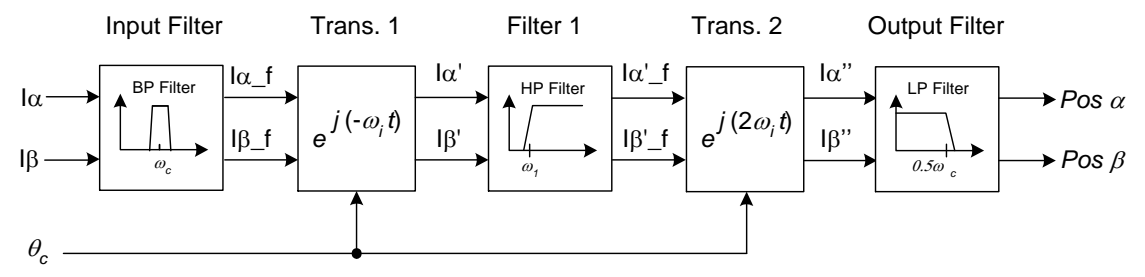

Fig. 1. Demodulation scheme to determine de saliency characteristics

This approach uses a band-pass filter (Input filter) tuned around $\omega_{\mathrm{c}}$ to remove those components not related to the carrier, note that $i_{\alpha \beta}$ are calculated from the three phase currents using a conventional $\alpha \beta$-transformation). The filtered signals $\left(i_{\alpha \beta_{-} \mathrm{f}}\right)$ are rotated once in the negative direction, so $i_{c p}$ is transformed into a base sequence $\left(i_{\alpha \beta}\right.$ ') so can be removed by a high-pass filter [26] (a bandwidth of $5 \mathrm{~Hz}$ was used here). A double rotation in the opposite direction is required now so the information related to $i_{c n}$ is given in a base-sequence ( $i_{\alpha \beta}$ "). Note that for a realistic machine, $\mathrm{i}_{c z}$ has been transformed into a positive sequence and should be removed. A low pass filter (Output filter) tuned at $0.5 \omega_{c}$ is usually suitable for this purpose [26]. Finally, the filtered signals denominated as $\operatorname{Pos}_{\alpha \beta}$ provide the saliency information and are represented by (6). Note that these are the components used to assess the health condition for the the monitoring scheme based on HF injection.

$$
\operatorname{Pos}_{\alpha \beta}=\frac{u_{c} \Delta L}{\omega_{c} L_{\sigma d} L_{\sigma q}} e^{j\left(\theta_{\delta}\right)}
$$

\subsection{Short Description of the INFORM Methodology}

Despite several techniques based on PWM transient excitation are reported [12-14], most of them are based on the INFORM (Indirect Flux Detection by On-line Reactance Measurement) methodology [12]. The INFORM method decomposes the reference voltage vector $\left(u_{\mathrm{ref}}\right)$ into basic vectors realizable by a three-phase inverter according to a SVPWM switching topology [28]. This procedure is shown in Fig.2a where the switching states are separated into six sectors numbered by $I, I I, \ldots V I$. The basic vectors $\left(\mathrm{V}_{1} \ldots \mathrm{V}_{6}\right)$ are represented by six active states, while the inactive states referred as null vectors are represented by $\mathrm{V}_{0}$ and $\mathrm{V}_{7}$. According to [28], for each switching cycle, two basic vectors (adjacent to vector $u_{\text {ref }}$ ) and two null vectors are applied in sequence. Fig. $2 \mathrm{~b}$ shows the case when $u_{r e f}$ is located in sector $I$. In this case the resulting switching sequence is 
$\mathrm{V}_{0} \rightarrow \mathrm{V}_{1} \rightarrow \mathrm{V}_{2} \rightarrow \mathrm{V}_{7} \rightarrow \mathrm{V}_{2} \rightarrow \mathrm{V}_{1} \rightarrow \mathrm{V}_{0}$. Fig.2c shows the stator equivalent circuit for a start connected machine for the case when $\mathrm{V}_{1}$ is applied, where $r_{\mathrm{s}}$ is the phase resistance, $e_{\mathrm{abc}}$ are the back-EMF terms, $u_{\mathrm{abc}}$ are the phase voltages, $i_{\mathrm{abc}}$ are the stator currents, and $l_{\sigma \mathrm{abc}}$ are the phase leakage inductances. The $\mathrm{d} / \mathrm{dt}$ current measurements can be represented by the circular current trajectories shown in Fig.2d. Basically as the rotor moves, the rotor anisotropy modulates $l_{\text {бabc }}$ which produce inductace modulatuion in the currents [26-27]. The aim of the approach is to estimate the saliency characteristics from the current measurements. This is not a simple task considering the influence of the resistive voltage drops and the back-EMF terms which produce significant variations in the current trajectories [25]. INFORM removes the influence of the unwanted terms by the application of two short-duration pulses (testing vectors), where the resulting current trajectories of two opposite vectors are subtracted to cancel the effects of the corresponding resistive-voltage drops and back-EMF terms [26-27]. The INFOM methodology including the switching pattern and sampling requirements are shown in Fig. 3 for the case when when $u_{\text {ref }}$ is located in sector $I$.

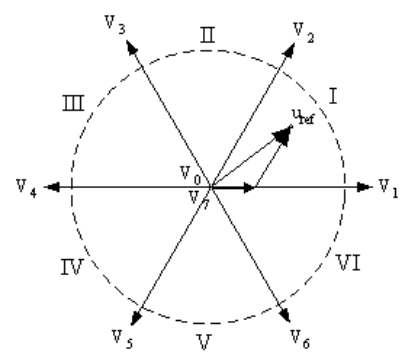

a)

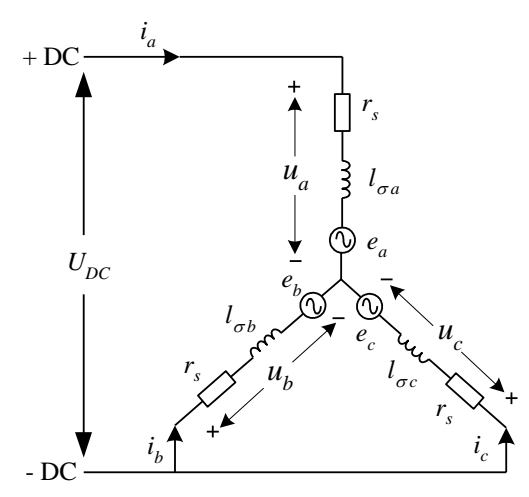

c)

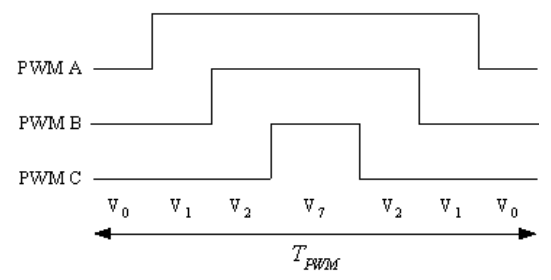

b)

B

c)

b)

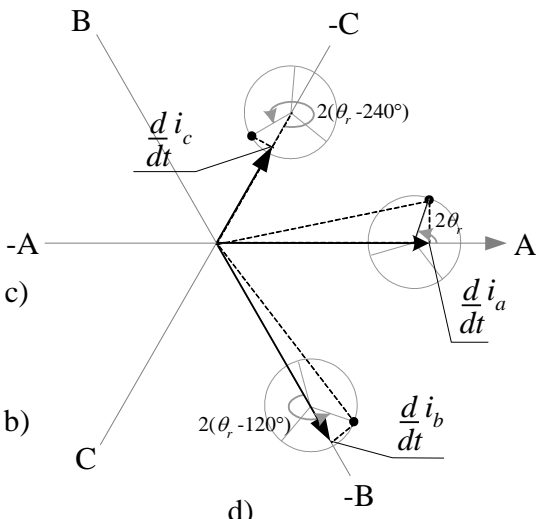

d)

Fig.2: INFORM methodology: a) SVPWM scheme, b) switching statuts when $U_{\text {ref }}$ is in Sector I, c) equivalent circuit of PMSM stator windings, d) current trajectories under the excitation vector $\mathrm{V}_{1}$.

According to [25], the testing vectors $\left(\mathrm{V}_{1} \rightarrow \mathrm{V}_{4}, \mathrm{~V}_{3} \rightarrow \mathrm{V}_{6}, \mathrm{~V}_{5} \rightarrow \mathrm{V}_{2}\right)$ are applied in sequence during the inactive state $\left(\mathrm{V}_{7}\right)$ [26-27], this as a method to avoid disruption of the average applied voltage [26]. Note that when the first vector has been applied, the resulting current trajectories should be sampled before the application of the second vector which corresponds to the opposite component of the vector initially applied. After application of the second vector, the resulting current trajectories are also measured and processed to estimate saliency.

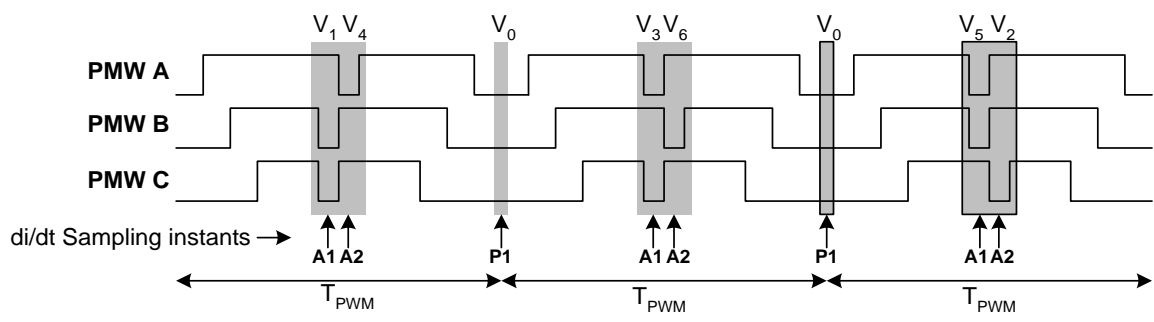


Fig.3: INFORM method: PWM sequence when $\mathrm{u}_{\text {ref }}$ is in the switching sector I

In its basic form INFORM requires three current $d / d t$ samples per switching cycle. These instants are indicated by arrows in Fig. 3 and can be described as follows: samples $A_{1}$ and $A_{2}$ (from active vectors) are obtained after the application of the opposite basic vectors which are applied in the middle of the inactive state $V_{7}$. Sample $P_{1}$ (from passive vector) is later obtained in the middle of the inactive state $\mathrm{V}_{0}$. Similar procedures are followed for

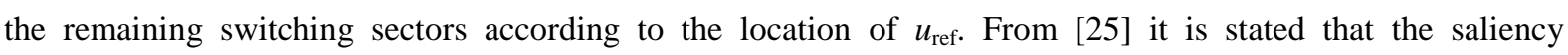
characteristics can be estimated from the phase inductances $L$ ' described as follows:

$$
\begin{gathered}
L_{a}^{\prime}=2-\frac{g}{2}\left(\frac{d}{d t} i_{a}^{(1)}-\frac{d}{d t} i_{a}^{(3)}\right) \\
L_{b}^{\prime}=2-\frac{g}{2}\left(\frac{d}{d t} i_{b}^{(3)}-\frac{d}{d t} i_{b}^{(6)}\right) \\
L_{c}^{\prime}=2-\frac{g}{2}\left(\frac{d}{d t} i_{c}^{(2)}-\frac{d}{d t} i_{c}^{(5)}\right) \\
\text { with } g=\frac{3 l_{0}\left(1-\left(\frac{\Delta L}{2 l_{0}}\right)^{2}\right)}{U_{D C}}
\end{gathered}
$$

where index "(x)" is used to denote the switching state, while $g$ is a constant value determined by $\mathrm{U}_{\mathrm{DC}}, l_{0}$ and $\Delta L$, while (+2) is the average value of the estimated inductances. From (7) it is clear that modulation due to the rotor anisotropy is determined by the difference of the current trajectories (direct and opposite vectors) [26] which confirm that the position estimates can be easily obtained from the di/dt measurements. According to this, the saliency position estimates $\left(\operatorname{Pos}_{a b c}\right)$ can be obtained by the removal of the offset component in (7) which gives:

$$
\begin{aligned}
& \operatorname{Pos}_{a}=\frac{g}{2}\left(\frac{d}{d t} i_{a}^{(1)}-\frac{d}{d t} i_{a}^{(4)}\right) \\
& \operatorname{Pos}_{b}=\frac{g}{2}\left(\frac{d}{d t} i_{b}^{(3)}-\frac{d}{d t} i_{b}^{(6)}\right) \\
& \operatorname{Pos}_{c}=\frac{g}{2}\left(\frac{d}{d t} i_{c}^{(2)}-\frac{d}{d t} i_{c}^{(5)}\right)
\end{aligned}
$$

Considering that INFORM is aimed primarily as a method to estimate the rotor position $\operatorname{Pos}_{a b c}$ is usually transformed into an $\alpha \beta$ reference frame which is obtained by (10). Note that these are the components used to assess the health condition for the monitoring scheme based on PWM transient excitation.

$$
\begin{gathered}
\operatorname{Pos}_{\alpha}=\operatorname{Pos}_{a}-\frac{1}{2}\left(\operatorname{Pos}_{b}+\operatorname{Pos}_{c}\right) \\
\operatorname{Pos}_{\beta}=\frac{\sqrt{3}}{2}\left(\operatorname{Pos}_{b}-\operatorname{Pos}_{c}\right)
\end{gathered}
$$

\subsection{Saliency-based Condition Monitoring}

The scheme to assess the drive's condition is the same developed and reported in [7] therefore is not described in full detail. As a quick remainder we can resume that the monitoring scheme combines saliency tracking information $\operatorname{Pos}_{\alpha \beta}$ (obtained by HF-injection, or in this case from INFORM) and an ideal saliency modulated profile (SMP) previously obtained when the machine is operating under healthy conditions $\left(\operatorname{Pos}_{\alpha \beta} *\right)$. This profile is normally obtained during commissioning and is stored in a lookup table according to the actual rotor position $\left(\theta_{\mathrm{r}}\right)$ and the torque demand information $\left(\mathrm{I}_{\mathrm{q}}{ }^{*}\right)$ available from the controller. Fig.4a shows the SMP for the machine considered in this study which was obtained by the INFORM approach (the methodology to calculate the SMP of a particular machine was described with detail in [7]). 

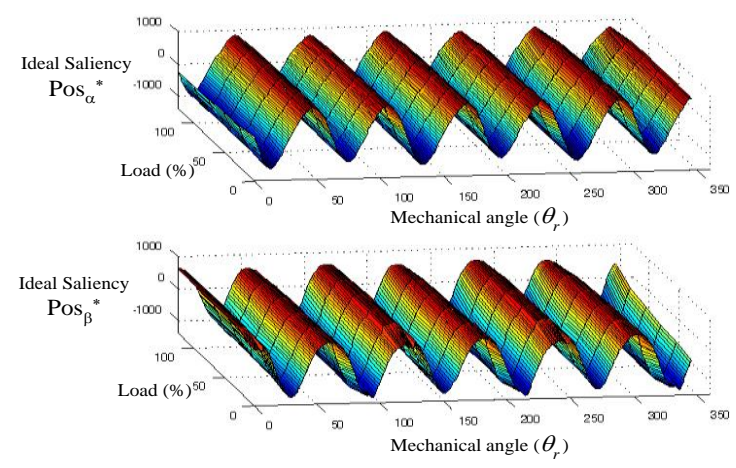

Fig.4: Electromagnetic profile of the evaluated machine obtained by INFORM

The approach to assess the drive's condition is shown in Fig.5; in this case $\operatorname{Pos}_{\alpha \beta}$ (obtained by HF-injection or INFORM) is compared against de ideal saliency $\left(\operatorname{Pos}_{\alpha \beta}{ }^{*}\right)$ extracted from the lookup table according to $\theta_{\mathrm{r}}$ and $I_{q}{ }^{*}$. The $\alpha \beta$ errors are combined to produce the saliency error $\left(E_{\text {saliency }}\right)$ which provides information of the salincy error respect to a system operating under healthy conditions.

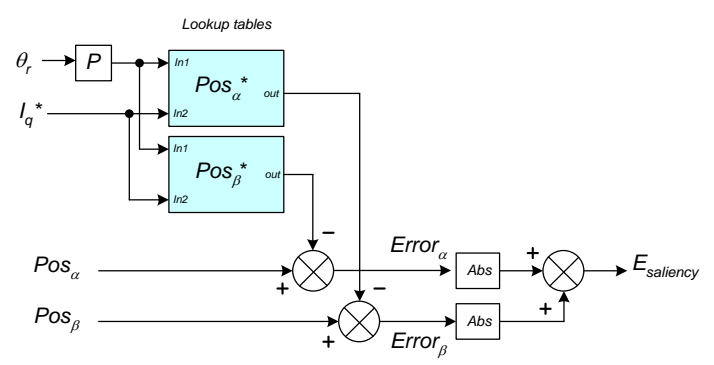

Fig.5: Saliency-based condition monitoring: calculation of the saliency error $\left(E_{\text {saliency }}\right)$

\section{EVALUATION OF HF-INJECTION AND INFORM TO ASSESS THE DRIVE CONDITION}

This section contains numerical and experimental results for the case of a PM-Servodrive subjected to the presence of inter-turn winding faults. The aim is to compare the two monitoring schemes under similar faults and operating conditions as a method to identify the best alternative to the development of monitoring schemes. For this purpose, the presence of full and incipient winding faults of several magnitudes will be evaluated under different operation modes.

The evaluated drive contains a 6-pole 3.82kW surface mounted PM motor which is shown in Fig.6; this machine has links to the stator windings brought out, so different combination of winding faults can be applied according to Fig.6c. A finite element (FE) representation of the evaluated machine was also developed which is shown in Fig.5b, this as a method to validate the experimental findings. The relevant parameters of the evaluated machine are contained in an Appendix. 

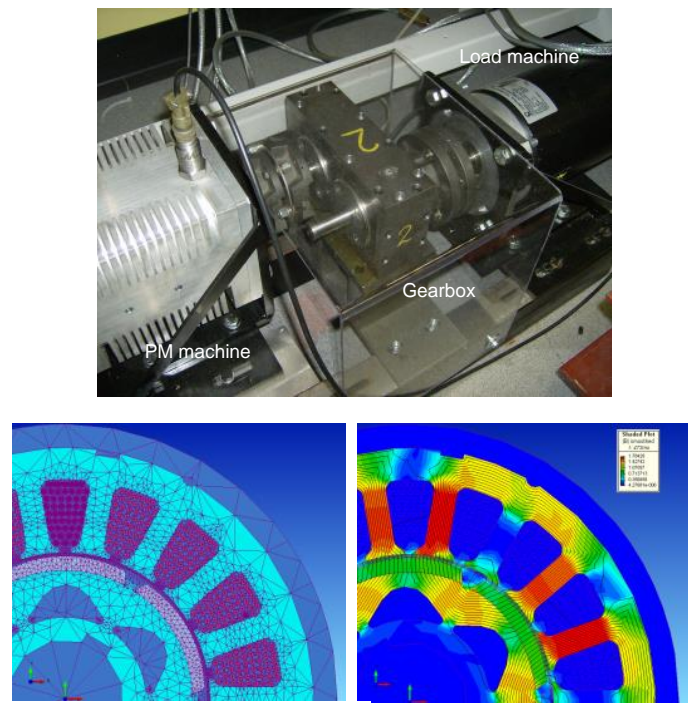

a)

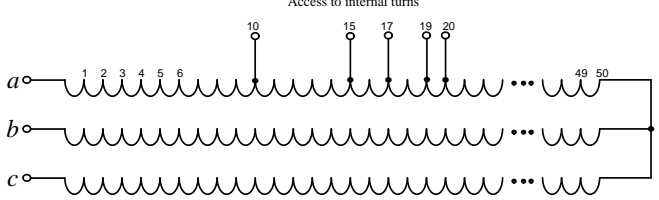

b)

c)

Fig.6: Evaluated PM motor; a) Experimental system, b) FE model, c) Connection of the windings.

\subsection{Numerical Evaluation}

As a first test, some numerical evaluations were obtained through a co-simulation between FE-software (MagNet) and Matlab/Simulink. In this case vector control, saliency tracking, and the monitoring approach were implemented in Simulink, while a FE model was used to improve accuracy respect to the realistic drive. In this test the machine is operated at 1000RPM, including a load of 50\%. Fig.7 shows the saliency error $\left(E_{\text {saliency }}\right)$ obtained through HF-injection (left side), and the INFORM approach (right side); the bottom graphs show $E_{\text {saliency }}$ respect to the rotor position, note that in this case the electrical angle is considered.

Note that in both cases the transition from a healthy to a faulty operation is evident when a turn-to-turn fault of several magnitudes is applied at $t=25 \mathrm{mSec}$. For this test the considered faults are: one-, two-, five-, and ten-turns (full short circuits). As expected $E_{\text {saliency }}$ remains very close to zero when the drive is operating under healthy conditions and changes considerably in the presence of faults (even for a very small fault). It is observed that the magnitude of both, the average value (DC) and the AC content increase as the number of affected turns grow. Since the frequency of the AC content changes according to rotor speed, the easiest solution to track changes on $E_{\text {saliency }}$ is by monitoring deviation on the average value. This can be easily obtained by a low pass filter (in this case a cutting frequency of $5 \mathrm{~Hz}$ was used).

Next section contains experimental evaluations in the presence of incipient and full inter-turn short circuits. 


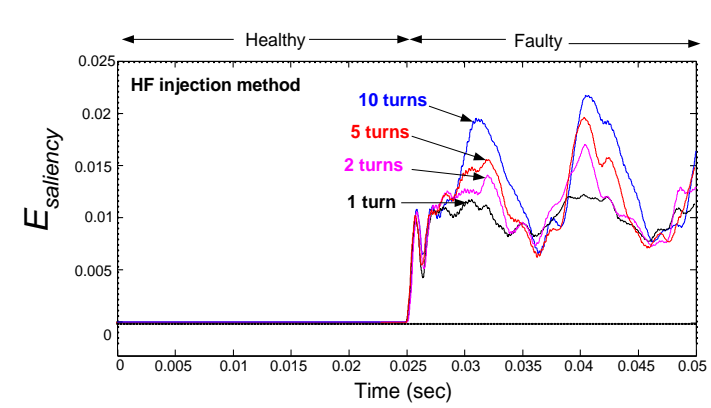

a)

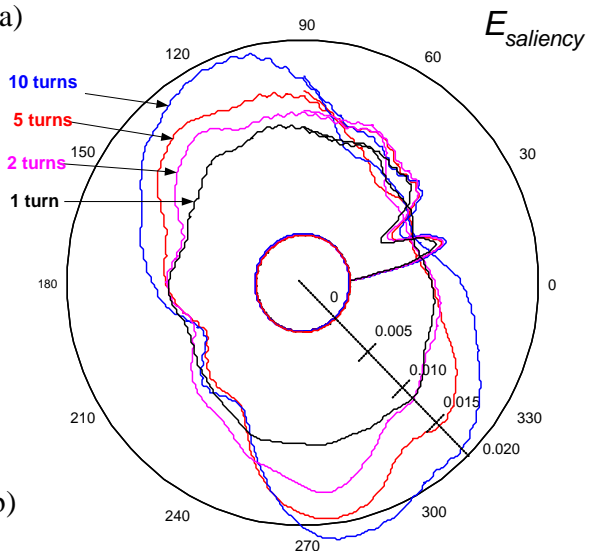

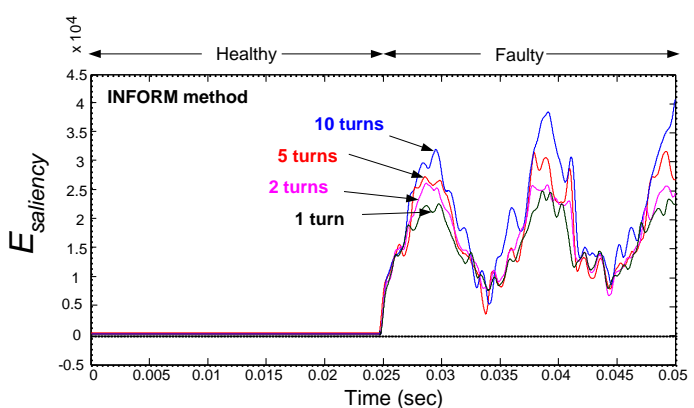

c)

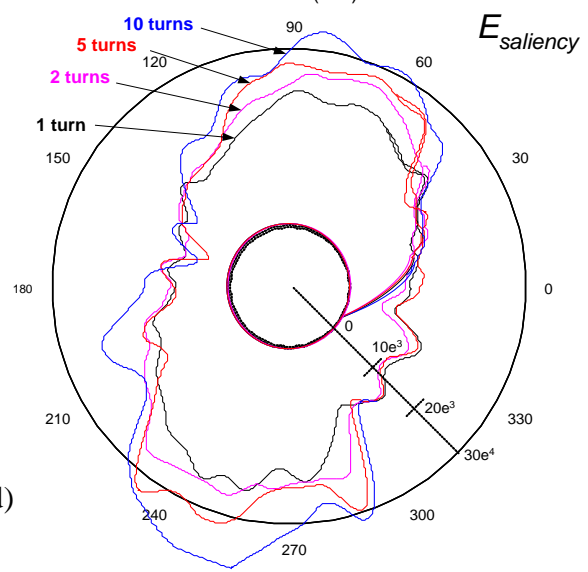

Fig.7: Numerical evaluation: response of $E_{\text {saliency }}$ in the presence of inter-turn short circuits: 1, 2, 5 and 10 turns (applied at $t=0.025 \mathrm{sec})$; Left: HF injection, Right: INFORM method

\subsection{Experimental Evaluation}

This section contains experimental results to evaluate the detection capabilities of HF-injection and PWM transient excitation. As a first test, the saliency characteristics are evaluated for two conditions: a healthy and a faulty operation. These results are shown in Fig.8, where the left-side graphs show $\operatorname{Pos}_{\alpha}$ and $\operatorname{Pos}_{\beta}$ for HFinjection, while graphs at the right show the same for the INFORM methodology. The top graphs represent the case when the machine is operated under healthy conditions while those at the bottom consider a faulty operation (in this case a one-turn full short circuit was applied in phase A). Note that for this test the machine is operated under steady state conditions (1000RPM, with 50\% load). It is clear that the fault produces a relevant impact in the saliency characteristics in both schemes, particularly for the case of component $\operatorname{Pos}_{\beta}$.

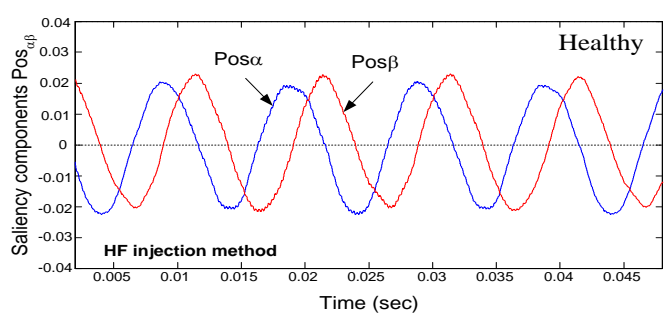

a)

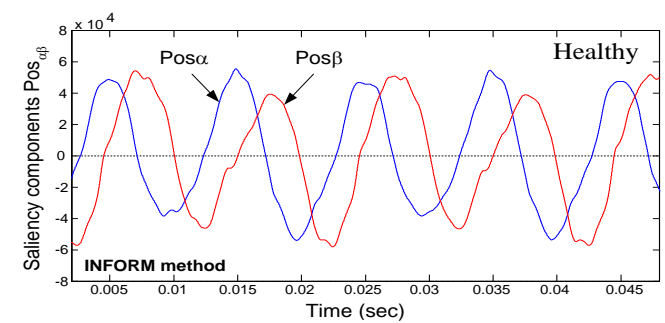

c)
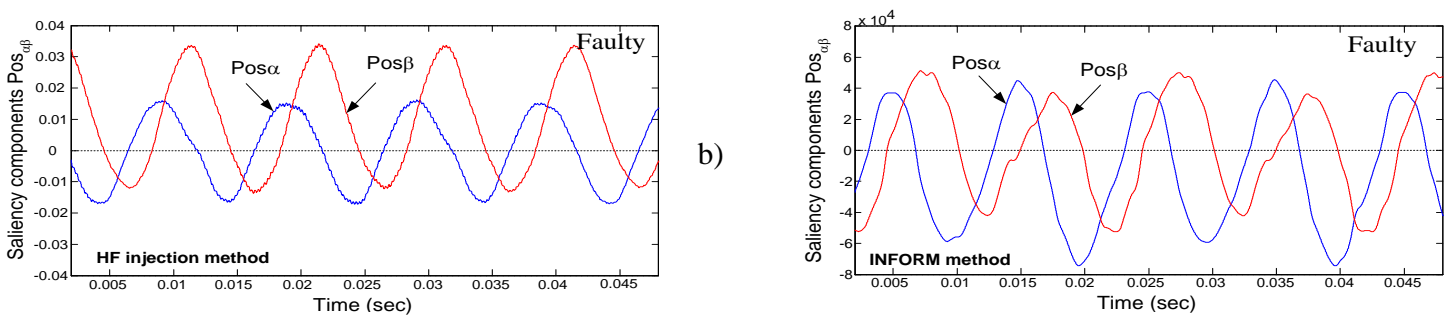

Fig.8: Experimental evaluation: comparison of the saliency components for: healthy machine (top graphs), and a faulty machine (bottom graphs); left side: HF injection, right side: INFORM method 

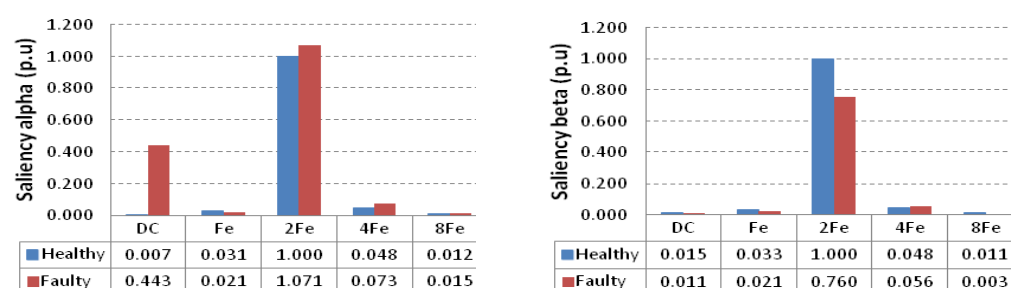

Table I: HF-injection: Harmonic content for: Pos $\alpha$ and Pos $\beta$
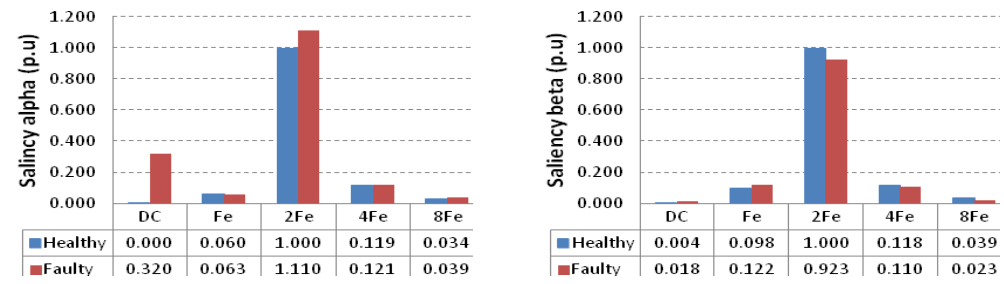

Table II: INFORM method: Harmonic content for: Pos $\alpha$ and Pos $\beta$

For visualization purposes, the impact of the fault is evaluated considering the harmonic content of $\operatorname{Pos}_{\alpha \beta}$ which are shown in Tables I and II. Note that $\operatorname{Pos}_{\alpha \beta}$ consist of a series of known harmonic components [29] which are: $F_{e}, 4 F_{e}, 8 F_{e}$ where $F_{\mathrm{e}}$ reefers to the fundamental excitation (electrical frequency). Note that further harmonics exits however due to their small magnitude, they are irrelevant. Note that all these harmonics are related to $2 F_{e}$ which is the main component normally used to track the saliency angle $\left(\theta_{\delta}\right)$. For the case of a faulty drive, the presence of a significant DC value for $\operatorname{Pos}_{\alpha}$ is evident, while $\operatorname{Pos}_{\beta}$ remains close to zero which is observable for both schemes. By looking at Tables I and II, it is clear that the DC component could be used to assess the drive condition; however since DFT is not suitable for nonstationary conditions, a health assessment based on this approach may not be desirable, therefore the approach shown in Fig.5 is advised.

The experimental evaluation of saliency-based condition monitoring is shown In Fig.9; in this case the machine is operating under steady state conditions (60RPM, while load is $80 \%$ ). For this test the presence of full and incipient inter-turn short circuits will be evaluated. Note that the presence of incipient winding faults is simulated by the connection of a low value resistor between the affected turns (1.0 ohm per turn was used) of a considered fault. In this test several magnitudes of winding faults are evaluated which include: one, three and five turns. Representation for $E_{\text {saliency }}$ in the presence of full short circuits is shown at the top, while those related to incipient faults are shown at the bottom. The graphs at the left side consider the case for HF-injection, while those at the right are based on the INFORM approach. The performance for the drive operating under healthy conditions is included for comparison purposes. 
Full short circuit faults
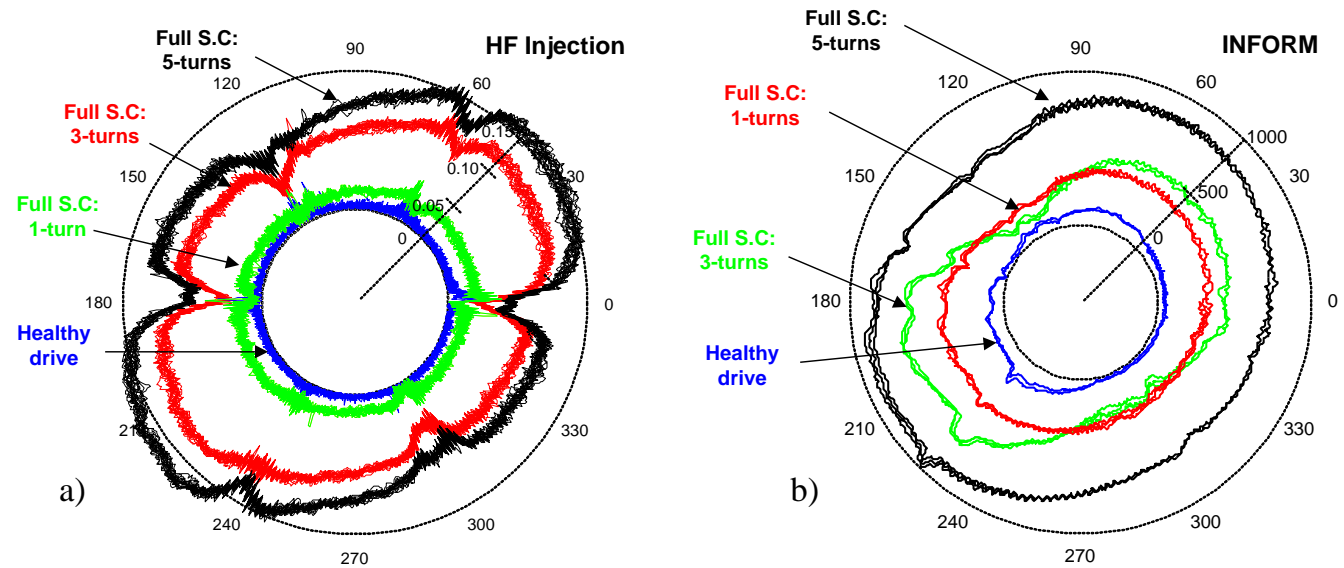

Incipient winding faults
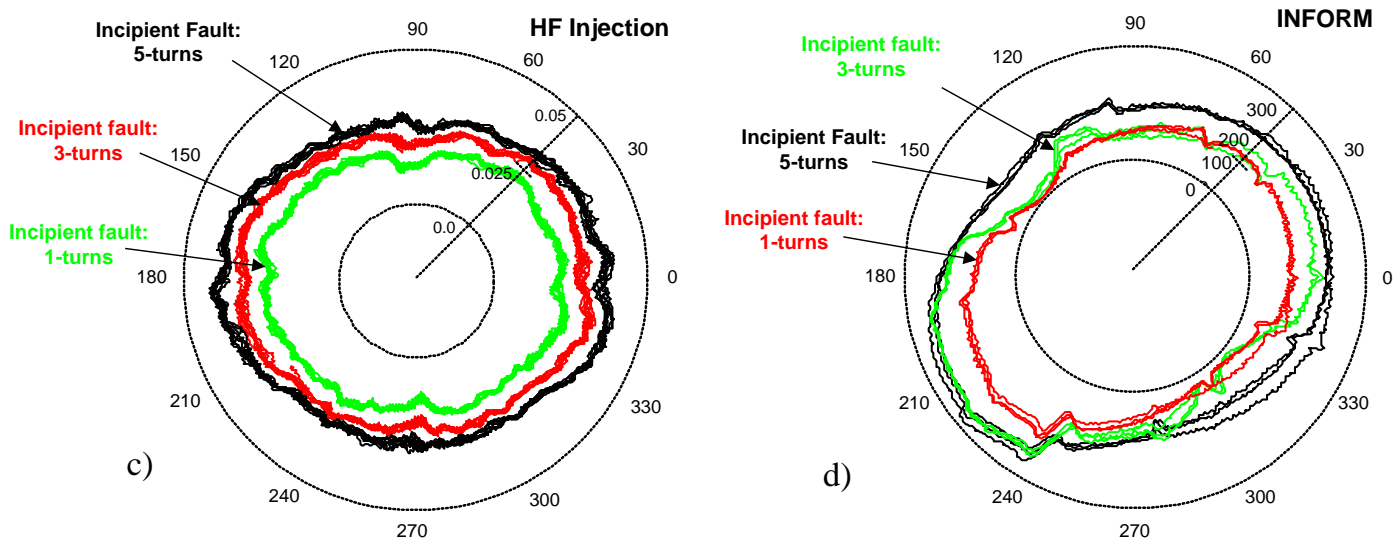

Fig. 9. Experimental evaluation: response of $E_{\text {saliency }}$ in the presence of inter-turn faults: 1, 3 and 5 turns; Left: HF injection,

Right: INFORM method; top graphs: full short circuits, bottom graphs: incipient winding faults.

From Fig.9a-b, it is clear that the saliency error has a low magnitude when the drive is operating under healthy conditions; the small deviations are produced by noise picked up during measurements and effects from the inverter and machine unbalances not considered by the SMP scheme. For the case of a faulty system, it is evident that $E_{\text {saliency }}$ changes considerably as the number of affected turns increase. It is clear that the inverter non-linearities have a relevant impact on $E_{\text {saliency }}$ for the case of HF-injection since 6 notches per electrical cycle are clearly observed. These are the result of dead-time effects as discussed in [29]. Note that for the case of INFORM, these notches are not observed as expected since the inverter nonlinearities become irrelevant.

Fig.9c-d shows the case when incipient faults are applied. Incipient faults were simulated by the connection of a small value resistor ( $1.0 \Omega$ per turn) between the affected turns, this to replicate a turn-to-turn insulation degradation condition. Several magnitudes of incipient faults are considered: one, three, and five-turns. As observed, the presence of these faults produces an increment of the DC component in $E_{\text {saliency }}$ in a similar fashion as in the case for full short circuits. Note that the DC component increases as the number of affected coils grow which confirm the capability not only to detected the presence of faults, but to determine their magnitude. As a final test, saliency tracking is evaluated in the presence of a full inter-turn short circuits under nonstationary and standstill operation. 
HF Injection method
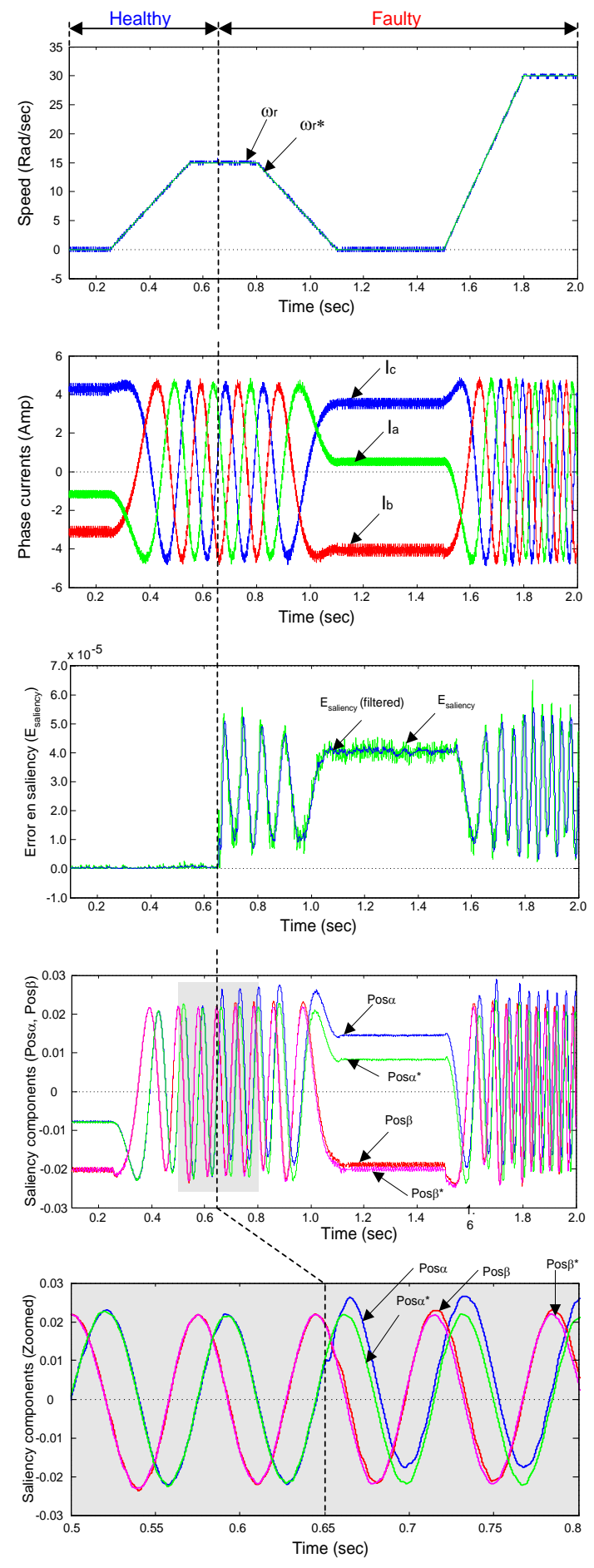

Inform method
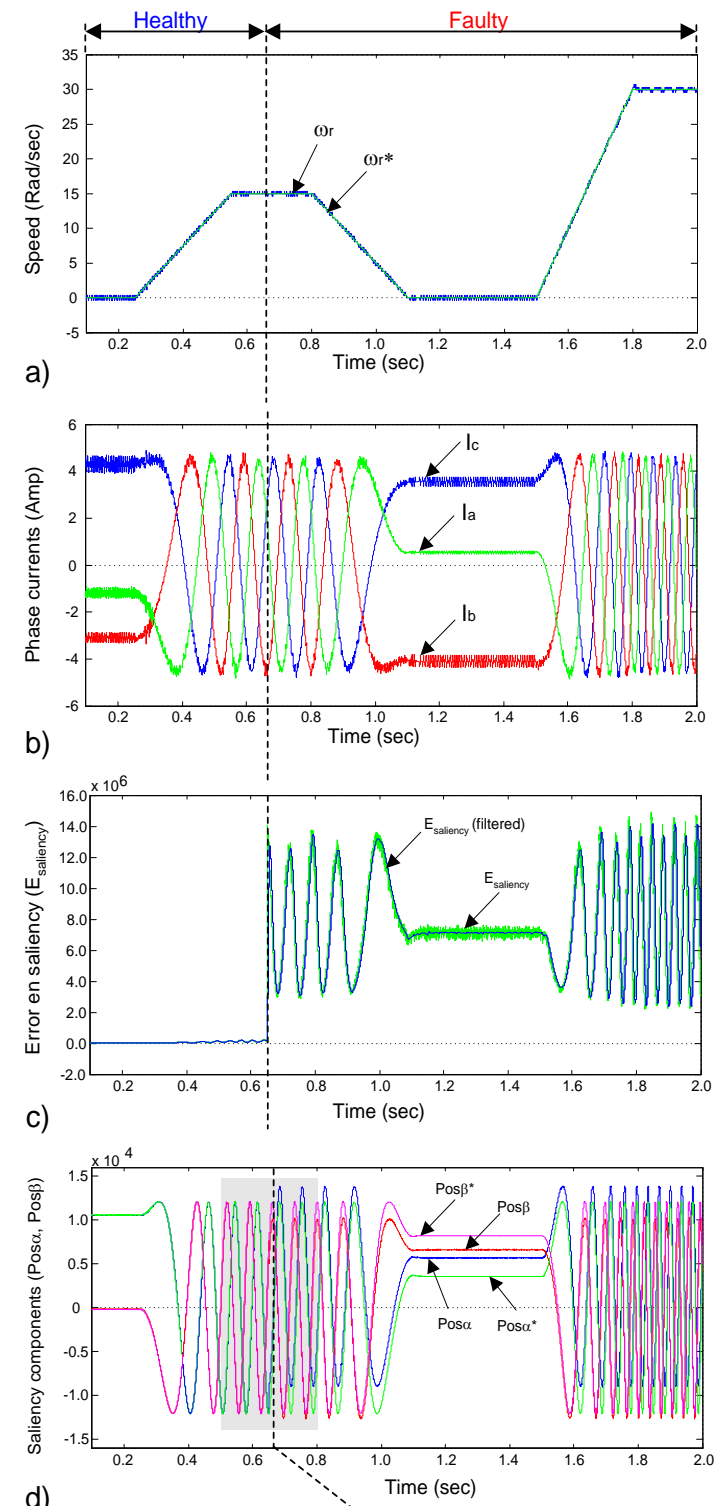

d)

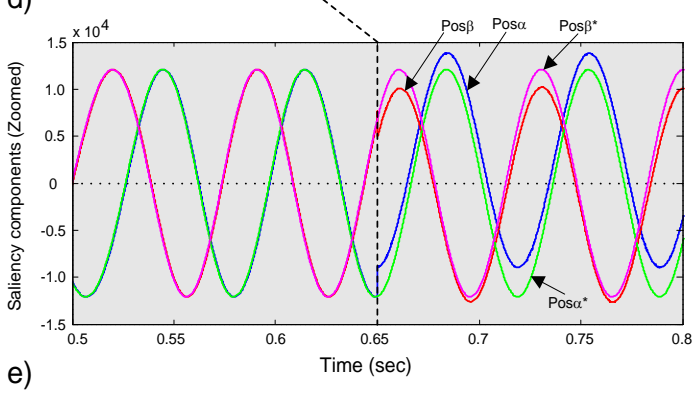

Fig. 10. Evaluation under nonstationary and standstill conditions when a fault is applied at $t=0.65$ sec. Left: HF-injection, Right: INFORM; a)Speed, b)current, c)Error in saliency, d)Saliency measurements, e)Detailed area of the saliency.

Fig.10 shows a comparison between HF-injection (left-side) and the INFORM methodology (right-side) when the drive is operated under speed control mode, so the machine is forced to follow a speed reference trajectory that changes continuously $\left(\omega^{*}\right)$. For this test a load of $50 \%$ is permanently applied, while the winding fault (short circuit of five turns) is applied at $t=0.65 \mathrm{sec}$. From Fig.10a, it is clear that the machine follows $\omega^{*}$ accurately which confirms that the presence of winding inter-turn faults hardly produces any significant disturbance in performance before degrading into major faults. The machine current measurements are shown in 
Fig.10b, the small distortions observed are produced by the saliency topologies used, i.e., a carrier signal for HF injection, and current transients due to the application of testing vectors for the case of INFORM.

The results for $E_{\text {saliency }}$ are shown in Fig.10c, where a low pass filter was used to clean out the signal. Note that $E_{\text {saliency }}$ remains very close to zero when the machine is operating under healthy conditions as expected, and changes considerably when the fault is applied. A relevant aspect is that despite the fault occurred when the drive was under steady state; a significant variation in $E_{\text {saliency }}$ remains during full operation which includes the presence of nonstationary and standstill conditions. The variations of $E_{\text {saliency }}$ (AC component) respect to position are expected according to Fig.7. Fig.10d show measurements of saliency $\left(P_{\alpha o}\right)$ compared to the SMP characteristics $\left(\operatorname{Pos}_{\alpha \beta} *\right)$. Details of the highlighted area in Fig.10d are shown in Fig.10e to appreciate with more detail the variations in the presence of a fault.

The presented results confirm the detection capabilities of saliency-based condition monitoring, and confirm that HF-injection and PWM transient excitation are suitable for nonstationary and standstill operation.

\subsection{Practical Aspects Related to INFORM}

As it was stated in Section 3.2, the INFORM approach (and all methods associated to PWM transient excitation), require $d / d t$ measurements to process the saliency characteristics. These measurements are expected to be very noisy [26-27] which may degrade the saliency characteristics. A simple way to reduce these distortions is the usage of $d / d t$ sensors instead of trying to calculate a discrete derivative in a conventional way. In this work, Rogowski coils and discrete low-pass filters with a cutting frequency of $250 \mathrm{kHz}$ are used to improve accuracy in the measurements [26]. Additionally, a short delay was also introduced before the $d / d t$ sampling after the application of the testing vector, this to allow dissipation of the residual energy; for this work a sampling delay of $10 n \mathrm{Sec}$ was found appropriate.

Another aspect related to INFORM (despite the complexity of the scheme), is the specific hardware requirements. For instance the application of the INFORM cycle interrupts the normal PWM pattern to the application of the testing vectors; similar situation occurs for the $d / d t$ current measurements which should sampled after the application of the testing vectors, including a sampling delay to reduce distortions. These hardware requirements can only be achieved by very flexible platforms which allow interruption of the PWM cycle for additional switching and sampling. For the experimental system used in this work, a very flexible DSP-FPGA embedded platform was used [26]. Fortunately the processing units of high performance drives are based on similar schemes which may facilitate adoption PWM transient excitation schemes not only for sensorless operation, but to assess the drive condition.

\section{CONCLUSIONS}

This paper shows that saliency tracking techniques can be used as a mechanism to provide improved condition monitoring in servodrives operating under nonstationary conditions. In this paper two representative saliency tracking schemes were evaluated: High frequency injection, and PWM transient excitation. Simulation and experimental results shows that despite both schemes use very different demodulation techniques, they share the advantage of having excellent detection capabilities which are maintained independently of the operating conditions (assuming their speed operating range is not exceeded). Further it was demonstrated that saliency- 
based condition monitoring is suitable for applications operating under nonstationary conditions, including standstill operation. A similar performance was observed which confirm that both schemes are suitable for the implementation of saliency-based condition monitoring topologies; therefore the selection of a suitable alternative will be determined by the operating conditions and flexibility of the processing unit. For instance, schemes based on HF-injection are relatively simple however they are only suitable for the medium-to-zero speed range applications. Schemes based PWM transient excitation has not speed range limitations; however the demanding hardware requirements are their main drawback.

APPENDIX

ELECTRICAL PARAMETERS FOR THE PM MACHINE

\begin{tabular}{|c|c|}
\hline Number of poles: & 6 \\
Type of magnets: & Surface mounted \\
Number of stator slots: & 18 \\
Turns per coil: & 50 \\
& \\
Rated speed: & $3000(\mathrm{rpm})$ \\
Rated torque: & $12.2(\mathrm{Nm})$ \\
Rated power: & $3.82(\mathrm{~kW})$ \\
Kt: & $1.6(\mathrm{Nm} / \mathrm{A})$ \\
Ke: & $98.0(\mathrm{Vrms} / \mathrm{krpm})$ \\
Inertia: & $\left.20.5(\mathrm{kgcm})^{2}\right)$ \\
R (ph-ph): & $0.94 \Omega$ \\
L (ph-ph): & $8.3 \mathrm{mH}$ \\
& \\
\hline
\end{tabular}

\section{REFERENCES}

[1] Motor reliability working group; "Report of large motor reliability survey of industrial and commercial installations, Part I," IEEE Trans. Ind. Applic., vol. IA-21, no. 4, pp. 853-864, Jul. 1985.

[2] Motor reliability working group; "Report of large motor reliability survey of industrial and commercial installations, Part II," IEEE Trans. Ind. Applic., vol. IA-21, no. 4, pp. 865-872, Jul. 1985.

[3] O. V. Thorsen and M. Dalva; "A survey of faults on induction motors in offshore oil industry, petrochemical industry, gas terminals, and oil refineries; IEEE Trans. Ind. Applic., vol. 31, no. 5, pp. 1186-1196, Sep./Oct. 1995.

[4] G. C. Stone, E. A. Boulter, I. Culbert, and H. Dhirani; "Electrical insulation for rotating machines: design, evaluation, aging, testing and repair". Piscataway, NJ: IEEE Press, 2004.

[5] A. Siddique, G. S. Yadava, and B. Singh; "A review of stator fault monitoring techniques of induction motors," IEEE Trans. Energy Convers., vol. 20, no. 1, pp. 1060-114, Mar. 2005.

[6] A. H. Bonnet and G. C. Soukup. "Cause and analysis of stator and rotor failures in three-phase squirrel-cage induction motors," IEEE Trans. Ind. Applic., vol 28, no. 4, pp. 921-937, Jul./Aug. 1992.

[7] J. Arellano-Padilla, M. Sumner and C. Gerada, "Winding condition monitoring scheme for a PM machine by using HF injection," IET Electric Power Applications Journal, 2011, vol. 5, Iss. 1, pp. 89-99.

[8] P. L. Jansen, and R. D. Lorenz, "Transducerless position and velocity estimation in induction and salient AC machines," IEEE Trans. Ind. Applic.,1995, 31, (2), pp. 240-247.

[9] M. W. Degner and R. D. Lorenz, "Using multiple saliencies for the estimation of flux, position and velocity in AC machines," in Conf. Rec. IEEE-IAS Annu. Meeting, New Orleans, LA, 1997, pp. 760.

[10] [21] C. A. Silva, G. M. Asher, M. Sumner and K. J. Bradley, "Sensorless rotor position control in a surface mounted PM machine using HF voltage injection," European power electronics and drives journal., Vol.13, Issue: 3, pp. 12-18, June 2003.

[11] T. M. Wolbank, M. K. Metwally; "Comparison of inherent saliency tracking methods for zero speed sensorless control of standard induction machines"; IEMDC'09 conference. Year: 2009, pp.1258-1263.

[12] M. Schroedl, "Sensorless control of AC machines at low speed and standstill based on the INFORM method", in Conf. Rec. IEEE Annu. Meeting, 1996, vol.1, pp.270-277.

[13] E. Robeischl, M. Schroedl, "Optimized INFORM measurement sequence for sensorless PM synchronous motor drives with respect to minimum current distortion"; IEEE Transaction of industry applications," Vol.40, pp.591-598, Mar/April 2004.

[14] P. Nussbaumer; T. M. Wolbank; "Saliency tracking based sensorless control of AC machines exploiting inverter switching transients"; SLED 2010 conference; Year:2010; pp.114-119.

[15] S. B. Lee, R. M. Tallam and T. G. Habetler, "A robust on-line turn-fault detection technique for induction machines base on monitoring the sequence component impedance matrix," IEEE Trans. Power Electron., vol. 18, no. 3, pp. 865872, May 2003.

[16] M. Arkan, D. K. Perovic, P. Unsworth, "Online stator fault diagnosis in induction motors", in Proc. Ins. Elect. Eng.Elect Power Applic., vol. 148, no. 6, pp. 537-547, Nov. 2001. 
[17] M. A. Cash, T. G. Habetler, G. B. Kliman, "Insulation failure prediction in AC machines using line-neutral voltages," IEEE Trans. Ind. Applic., vol 34, no. 6, pp.1234-1239, Nov./Dec. 1998.

[18] J. H. Hung, J. J. Lee, B. H. Kwon, "Online diagnosis of induction motors using MCSA," IEEE Trans. Ind. Electron., vol. 53, no. 6 pp. 1842-1852, Dec. 2006.

[19] F. C. Trutt, J. Sottie, J. L. Kohler, "Condition monitoring of induction motors stator winding using electrically excited vibrations," in Conf. Rec. 37 ${ }^{\text {th }}$ IEEE IAS Annu. Meeting, Oct. 13-18, 2002, vol. 4, pp. 2301-2305.

[20] T. Assat, H Henao, G. A. Capolino, "Simplified axial flux expectrum method to detect incipient stator inter-turn shortcircuits in induction machine," in Proc. IEEE Int. Symp. Ind Electron., May 4-7, 2004, vol. 2, pp.815-819.

[21] Z. Chen, R. Oi, H. Lin, "Inter-turn short circuit fault diagnosis form PMSM based on complex gauss wavelet"; IEEE Int. Conf. on Wavelet. Analysis and pattern recognition; Nov. 2007, pp.1915-1919.

[22] B. Aubert, J. Regnier, S. Caux, D. Alejo, "Stator inter-turn short-circuit detection in permanent magnet synchronous generators using extended Kalman filtering"; $11^{\text {th }}$ IEEE Int. workshop of Elect. Meas. Sign. and their App. to Mech. ECMSM'2013; pp.1-6; 2013.

[23] P. Werynski, D. Roger, R. Corton, J. F. Brudny, "Proportion of a new method for in-service monitoring of the aging of stator winding insulation in AC motors," IEEE Trans. Energy Convers., vol 21, no. 3, pp.673-681, Sep. 2006.

[24] F. Briz, M. W. Degner, A. B. Diez, J. M. Guerrero, "On-line diagnostics in inverter-fed induction machines using highfrequency signal injection," IEEE Trans on Ind. Applic., Vol.40, No.4, July/August 2004; pp.1153-1161.

[25] F. Briz, M. W. Degner, A. Zamarron, J. M. Guerrero, "On-line stator winding fault diagnosis in inverter-fed AC machines using high frequency signal injection", IEEE Trans. on Ind. Applic., vol.:39, No.4, pp. 1109-1117, Jul. 2003.

[26] H. Yahan, "Sensorless control of surfaced permanent magnet machine using fundamental PWM excitation," Ph.D. Dissertation, Dept. Electrical \& Electronic Engineering, University of Nottingham, 2009.

[27] H. Yahan, M. Sumner, G. Asher and Q. Gao, "Sensorless control for a PM machine with reduced current distortion using space vector PWM excitation," in Proc. $13^{\text {th }}$ EPE Conference, 2009.

[28] P. G. Handley, J. T. Boys, "Space vector modulation: an engineering review"; $4^{\text {th }}$ International conference on power electronics and variable speed drives; London, UK. Jul 1991, pp.87-91.

[29] C. Silva, G. Asher, M. Sumner, "Influence of dead-time compensation on rotor position estimation in surface mounted PM machines using HF voltage injection,” in Proc. Power Conv. Conf. PCC-Osaka 2002. Vol.3, pp. 1279-1284.

[30] F. Briz, M. W. Degner, J. M. Guerrero, A. B. Diez, "Temperature estimator in inverter-fed machines using high frequency carrier signal injection," in Conf. rec. 42 ${ }^{\text {nd }}$ IEEE IAS Annu. meeting, Sep. 23-27, 2007, pp. 2030-2037. 